\title{
Development of a One-Step Multiplex Real-Time PCR Assay for the Detection of Viral Pathogens Associated With the Bovine Respiratory Disease Complex
}

\section{OPEN ACCESS}

Edited by:

Annamaria Pratelli,

University of Bari Aldo Moro, Italy

Reviewed by:

Wojciech Socha,

National Veterinary Research Institute

(NVRI), Poland

Ivan Toplak,

University of Ljubljana, Slovenia

$$
\begin{array}{r}
\text { *Correspondence: } \\
\text { Xin Yin } \\
\text { yinxin@caas.cn } \\
\text { Yuanmao Zhu } \\
\text { zhuyuanmao@caas.cn } \\
\text { Fei Xue } \\
\text { xuefei@caas.cn }
\end{array}
$$

Specialty section:

This article was submitted to Veterinary Infectious Diseases,

a section of the journal

Frontiers in Veterinary Science

Received: 30 November 2021 Accepted: 04 January 2022 Published: 26 January 2022

Citation:

Zhang J, Wang W, Yang $M$, Lin J, Xue F, Zhu Y and Yin X (2022) Development of a One-Step Multiplex Real-Time PCR Assay for the Detection of Viral Pathogens Associated With the Bovine Respiratory Disease Complex.

Front. Vet. Sci. 9:825257. doi: 10.3389/fvets.2022.825257

\author{
Juan Zhang, Wan Wang, Mujiao Yang, Jun Lin, Fei Xue*, Yuanmao Zhu* and Xin Yin* \\ State Key Laboratory of Veterinary Biotechnology, Division of Livestock Infectious Diseases, Harbin Veterinary Research \\ Institute of Chinese Academy of Agricultural Sciences, Harbin, China
}

Bovine respiratory disease complex (BRDC) occurs widely in cattle farms. The main viral pathogens include bovine viral diarrhea virus (BVDV), Bovine herpesvirus 1 (BoHV-1), bovine parainfluenza virus type 3 (BPIV3), and bovine respiratory syncytial virus (BRSV), and the newly emerged influenza D virus (IDV). In this study, we have developed a one-step multiplex real-time Polymerase Chain Reaction (PCR) capable of simultaneously detecting these five viral pathogens causing BRDC. The established assay could specifically detect targeted viruses without cross-reaction with others. The detection limit was $\sim 10$ copies/reaction for single real-time PCR and 100 copies/ reaction for multiplex real-time PCR assay. A total of 213 nasal samples from cattle with signs of respiratory tract disease were then collected for performance evaluation of the established platform, proving that the method has good specificity and sensitivity. The surveillance data suggested that BVDV and BoHV-1 infections are the dominant cause of BRDC in the herd, whereas the detection rate of IDV, BIPV3, and BRSV is relatively lower. In summary, the established assay provides technical support for rapid clinical detection of BRDC associated viral pathogens to guide the formulation of BRDC prevention and control measures.

Keywords: BRDC, IDV, BVDV, BoHV-1, BRSV, BPIV3, quantitative PCR

\section{INTRODUCTION}

Bovine respiratory disease complex (BRDC) has posed a great threat to the dairy and beef industries throughout the world (1). The disease is usually resulted from stress, primary viral infection and secondary bacterial infection, leading to high mortality and morbidity in cattle $(2,3)$. It's considered that single or combinational infections by viral pathogens are the prerequisites to developing BRDC (4). So far, the viral pathogens including Bovine Viral Diarrhea Virus (BVDV), Bovine herpesvirus 1 (BoHV-1), Bovine Parainfluenza Virus Type 3 (BPIV3), Bovine Respiratory Syncytial Virus (BRSV) and Influenza D Virus (IDV) have been proposed to be directly associated with BRDC (5). Moreover, secondary bacterial infections such as Mannheimia haemolytica, Pasteurella multocida, and Haemophilus somnus during or after viral infections potentially cause fatal complication of viral infections $(6,7)$. Thus, early diagnosis of viral pathogens associated with each outbreak could be beneficial to timely managing and controlling BRDC (1). 
BVDV is single-stranded, positive-sense RNA viruses that belongs to genus Pestivirus, family Flaviviridae (8). BVDV are genetically divided into genotype 1 (BVDV-1), genotype 2 (BVDV-2) and genotype 3 (BVDV-3) (9). Previous studies have concluded that BVDV aggravates the respiratory disease syndrome by causing immune tolerance and persistent infection (10). BoHV-1 harbors a linear double-stranded DNA genome and causes infectious bovine rhinotracheitis (IBR), a highly contagious infectious respiratory disease $(11,12)$. The World Organization for Animal Health (OIE) lists IBR as a Category $\mathrm{B}$ animal disease. As reported, BoHV-1 preferentially infects the basal epithelium of injured monolayers and/or genital tracts to induce mucosal barrier injury $(13,14)$. Serological survey of BoHV-1 infection in China suggested that the seropositive rate was approximately $40 \%$ (11). Unlike BoHV-1, BPIV3 is restricted to replicate in the apical ciliated epithelium causing tissue damage and immunosuppression which often progresses to bronchial pneumonia in calves and adult cattle (15). BRSV infection is the major cause of BRDC in calves during their first year (16). It infects both ciliated bronchial epithelia and type II pneumocytes, and causes minimal to extreme respiratory diseases (17). In addition to these well-known viral pathogens, IDV, a new type of influenza virus with cattle as a primary reservoir, can infect and cause influenza diseases in cattle (18). Recently, IDV was reported as a crucial viral agent that drives the occurrences of bovine respiratory disease syndrome (18). However, the contribution of IDV to the bovine respiratory disease development as well as the co-infection between IDV and other respiratory viral pathogens remains unknow. Due to the similarity of clinical signs and co-infections involved in BRDC, it's nearly impossible to rapidly and accurately identify the causative agents solely based on the clinical signs and conventional methods such as pathogens isolation. Therefore, single and multiplex real-time PCR assays have been developed for the rapid detection of pathogens associated with BRDC in the past years $(13,17,19-21)$. However, the single target realtime PCR requires separate amplification by consuming excess resources along with inefficient processing. Direct diagnostic methods assay for the presence of the viruses associated with BRDC are still lacking. In addition, the relative contribution of these viruses in BRDC development has not been defined yet, especially in China (22). In this study, we developed a multiplex real-time PCR assay for synchronously detecting five viral pathogens associated BRDC. We showed that the optimized assay displayed excellent performance. The detection limits for all these five viral pathogens were 100 copies/reaction with the multiplex real-time PCR assay. More importantly, our established assay can effectively detect BRDC related pathogens from the nasal swabs collected from the cattle with signs of respiratory tract disease.

\section{MATERIALS AND METHODS}

\section{Viruses and Cell Cultures}

BVDV-1a NADL strain (ATCC VR-534), Bovine rotavirus (BRV) strain NCDV (ATCC VR-452) Pasteurella multocida P-1059 (capsular serogroup A) were obtained from China Veterinary Culture Collection Center (CVCC). BoHV-1 isolate HLJ07,
BRSV field isolate HLJ01, Bovine coronavirus (BCoV) isolate HM and Mannheimia haemolytica SH1801 (Serotype 1), and BPIV-3 (HQ530153) were isolated by our laboratory (23). BVDV-2 HLJ-10 strain was provided by Dr. Mingchun Gao at Northeast Agricultural University (24). The Nucleic Acid of CSFV vaccine strain (C-strain) was provided by Dr. HuaJi Qiu at Harbin Veterinary Research Institute of Chinese Academy of Agricultural Sciences (25). BVDV, BoHV-1, BPIV3 were propagated on Madin-Darby bovine kidney (MDBK) cells. BRSV was propagated on bovine Turbinate (BT) cells cultured in Minimum Essential Medium (MEM) (Thermo Fisher, Inc.; USA) supplemented with $2 \%$ bovine serum (GE, Inc.; USA). IDV strain D/bovine/Mississippi/C00046N/2014 was obtained via reverse genetics system and propagated on Madin-Darby Canine Kidney (MDCK) cells (26).

\section{Primer and Probe Design}

All available sequences of BVDV, BoHV-1, BRSV, BPIV3 and IDV were retrieved from GenBank for alignment via MEGA X. To obtain the specific primer/probe set for the assay development, we selected the highly conserved regions BVDV 5'UTR region, BoHV-1 glycoprotein E $(g E)$ gene, BRSV nucleocapsid $(N)$ gene, BPIV3 matrix $(M)$ gene, IDV $P B 1$ gene for primer/probe design using the Oligo7 and Primer Express 3.0.1 software. The designed primer/probe sets were then subjected to Primer-BLAST for specificity validation. The primer/probe sets with excellent specific properties were finally chosen for the assay development. All oligonucleotides listed in Table 1 were synthesized by RuiBiotech (Beijing, China).

\section{Nucleic Acid Extraction}

DNA/RNA was extracted from cell cultures or clinical samples following the instruction of Axygen Body Fluid Viral DNA/RNA Miniprep Kit. Briefly, $2 \mathrm{~mL}$ of DMEM was added into the nasal swabs and mixed well. After centrifugation at 5,000 rpm for $5 \mathrm{~min}$, the clarified supernatants were then collected and used for nucleic acid extraction. To obtain the DNA/RNA from either clinical samples or infected culture fluids, $200 \mu \mathrm{L}$ of the supernatants were mixed with equal amount of lysis buffer. After incubation at room temperature for $5 \mathrm{~min}$, the mixture was mixed with $75 \mu \mathrm{L}$ of $\mathrm{V}-\mathrm{N}$ buffer. The supernatants were then collected after centrifugation for RNA extraction. Finally, the resulting RNA was eluted using $30 \mu \mathrm{L}$ elution buffer and stored at $-80{ }^{\circ} \mathrm{C}$ for further use.

\section{Virus Titration on Cell Cultures}

BVDV, BoHV-1, and BPIV3 were propagated in MDBK cells. Briefly, the monolayer MDBK cells were inoculated with the indicated virus stock at MOI of 0.02. After one hour adsorption, the cultures were rinsed and washed three times with PBS. DMEM supplemented with $2 \%$ horse serum was then added for maintenance. The cell cultures are collected once $100 \%$ cytopathic effect $(\mathrm{CPE})$ is observed. The $\mathrm{TCID}_{50}$ values were determined using standard methods after incubation for $48-120 \mathrm{~h}$. 
TABLE 1 | Primer and probes used in this study.

\begin{tabular}{|c|c|c|c|c|}
\hline Pathogens & Primer or probes & Sequence (5'-3') & Position & Length \\
\hline \multirow[t]{3}{*}{ BVDV } & BVDV-F228 & TCGAGATGCCACGTGGAC & $228-245$ & $162 \mathrm{bp}$ \\
\hline & BVDV-UTR & ATGTGCCATGTACAGCAGA & $371-390$ & \\
\hline & BVDV-Pro & CY5-ACCCTATCAGGCTGT-MGB & $322-337$ & \\
\hline \multirow[t]{3}{*}{$\mathrm{BOHV}-1 \mathrm{BoHV}-1$} & gE-85bp-F & CCGCCAATAACAGCGTAGA & $122735-122753$ & $85 \mathrm{bp}$ \\
\hline & gE-85bp-R & CCGTTGTACTGCAGCACAA & $122801-122819$ & \\
\hline & BOHV-1-gE-Pro & FAM-CCTCCGGGCTTIAC-MGB & $122783-122796$ & \\
\hline \multirow[t]{3}{*}{ BRSV } & BRSV-N-141bp-F & ATACAAAGGACTCATCCCGAAAG & $155-173$ & $75 \mathrm{bp}$ \\
\hline & BRSV-N-141bp-R & AАGATTCСТTСTAСССТАСТАССТСС & $201-220$ & \\
\hline & BRSV-N-Probe & NED-AGTATITGAAAAGTACCCTC-MGB & $178-192$ & \\
\hline \multirow[t]{3}{*}{ BPIV3 } & BPIV3M-113bp-F & CAGGAACTCCTACAAGCCGC & $164-183$ & $113 \mathrm{bp}$ \\
\hline & BPIV3M-113bp-R & CATGGGTACAGTTCAGGTTAATG & $317-338$ & \\
\hline & BPIV3-MTPro & VIC-CTATCATCTCCGTGGC-MGB & $218-237$ & \\
\hline \multirow[t]{3}{*}{ IDV } & IDV-F (19) & АATTCTGTGCCAATGAAGCTG & $320-340$ & $104 \mathrm{bp}$ \\
\hline & IDV-R (19) & TGGCATATTTCTITCACTTGTCC & $401-423$ & \\
\hline & IDV-Pr & ROX-CATAAGTTTGYCTTCCTTCAGTG-MGB & 375-397 & \\
\hline
\end{tabular}

\section{Sensitivity Test}

To determine the lowest detection limit of primers and probes used in this study, the specificity tests of single real-time PCR and multiple real-time PCR were conducted in single tube. Liner positive control with the copy number ranging from $10^{7}$ to $10^{1}$ was used as standards.

\section{Real-Time PCR}

The fixed reaction conditions for the multiplex reaction system were as follow: $10 \mu \mathrm{L}$ of $2 \times$ one step RT-PCR buffer III (Takara), $0.4 \mu \mathrm{L}$ of Ex Taq HS, $0.4 \mu \mathrm{L}$ of PrimeScript RT Enzyme Mix II, $0.1 \mu \mathrm{L}$ of each primer set $(10 \mu \mathrm{mol}), 0.2 \mu \mathrm{L}$ of Probe $(10 \mu \mathrm{mol})$, $2 \mu \mathrm{L}$ of nucleic acid template, and enzyme-free water $5.7 \mu \mathrm{L}$. Amplification was carried out using the following program: $42^{\circ} \mathrm{C}$, $5 \mathrm{~min}, 95^{\circ} \mathrm{C}, 10 \mathrm{~s}, 45$ cycles of $95^{\circ} \mathrm{C} 5 \mathrm{~s}, 60^{\circ} \mathrm{C} 30 \mathrm{~s}$.

\section{Clinical Samples}

A total of 213 nasal swab samples were collected from the cattle with signs of respiratory tract disease in the northeastern part of China. Among them, 30 nasal swabs were collected from dairy herds in 2019, 38 nasal swabs were collected from dairy herds in 2020, while the remaining 145 nasal swabs were collected from dairy herds in 2021. Most these sampled animals had either one or several of the following symptoms: fever $>39^{\circ} \mathrm{C}$, cough, serious nasal and/or lacrimal discharge, and breath sounds. The nasal samples were stored frozen at $-80^{\circ} \mathrm{C}$ until use.

\section{RESULTS}

\section{Analytical Specificity of the Primer/Probe Sets Used in the One-Step Real-Time RT-PCR Assay}

To experimentally evaluate the specificity of the selected primer/probe sets, we isolated the viral genomes from the cultured viruses including BVDV NADL strain, BoHV-1 isolate HLJ07, BPIV3 strain HQ510351, BRSV field isolate HLJ01,
IDV strain D/bovine/Mississippi/C00046N/2014, BCoV isolate $\mathrm{HM}$ and BRV strain NCDV as well as the bacterial genomes from Pasteurella multocida and Mannheimia haemolytica for testing. We found that the designed primer/probe set could successfully recognize and amplify the gene fragment derived from the corresponding virus. No amplification and fluorescent signals were observed for non-related pathogens (Figures 1A-E). These results proved that each set of primers and probes exhibited good specificity which can be applied for the assay development.

\section{Establishment of the Standard Curve for the Multiplex Real-Time PCR}

To further verify the sensitivity of the multiplex detection method, we generated the recombinant plasmids containing the five target fragments amplified from IBPV3 [ $M$ gene (40394194)], BoHV-1 [gE gene (120290-123438)], BVDV-1b [5'-UTR (64-494)], BRSV [ $N$ gene (1342-2289)], and IDV [PB1gene (129$488)$ ] and cloned into pLVX-IRES-zsGreenI vector created by Clontech Laboratories Inc. The primers used for amplification were shown in Table 2, respectively. The standard curves for the five detected viruses were then determined using a range of 10 -fold diluted recombinant plasmids with concentrations from $10^{7}$ to $10^{1}$ copies/ $\mu$ L. The qPCR amplifications of each standard plasmid DNA showed amplification plots corresponding to mean Ct values of 16.272-35.966 for BVDV, 15.697-35.694 for BoHV1, 17.563-36.402 for IBPV3, 20.394-39.084 for BRSV, 17.38536.634 for IDV (Figures 2A-E left panel). The slope of the standard curve, correlation coefficient $\left(\mathrm{R}^{2}\right)$, and amplification efficiency (Eff\%) were calculated as follows: $-3.125,0.999$, and $108.905 \%$ for BVDV; $-3.312,0.992$, and $100.424 \%$ for BoHV$1,-3.206,0.999$, and $105.053 \%$ for BPIV3, $-3.322,0.995$, and $100.104 \%$ for BRSV, $-3.165,0.990$, and $107.012 \%$ for IDV (Figures 2A-E right panel), showing an excellent amplification efficiency and linear equation required for RNA quantification. 


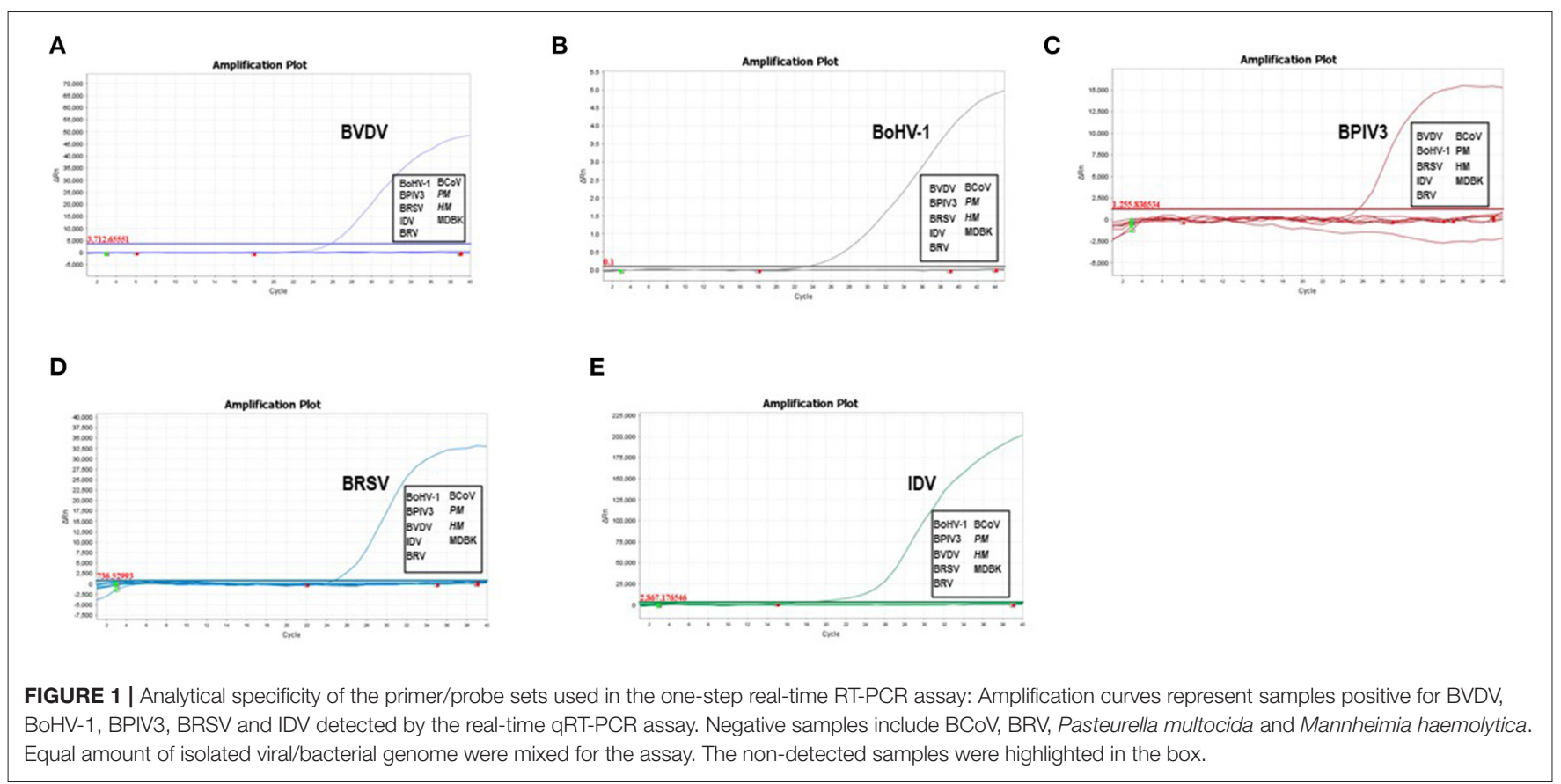

TABLE 2 | Primers used for standard constructions.

\begin{tabular}{|c|c|c|c|c|}
\hline Pathogens & Primer or probes & Sequence (5'-3') & Position & Length \\
\hline \multirow[t]{2}{*}{ BVDV } & BVDV-F54 & CCGGAATTCCGGGACAAATCCTCCTTAGCGAA(EcoRI) & $64-85$ & $450 \mathrm{bp}$ \\
\hline & BVDV-2F54 & CGC ctcgag TCTCСTCTCTCGCCAAACA(Xhol) & $476-494$ & \\
\hline \multirow[t]{2}{*}{$\mathrm{BOHV}-1$} & $\mathrm{BOHV}-1-\mathrm{gl}-\mathrm{gE}-\mathrm{L}$ & gttaTCTAGAgtgatggtgatggtgatgGCGGAGGATGGACTTGAGTCG(xba I) & $120290-120309$ & $3188 \mathrm{bp}$ \\
\hline & $\mathrm{BOHV}-1-\mathrm{g} 3 \mathrm{E}-\mathrm{U}$ & GATC gactagt CGGTGCCTGTTGCTCTGGAT(Spel I) & $123418-123438$ & \\
\hline \multirow[t]{2}{*}{ BRSV } & BRSV-NF2 & GATCGACTAGTC GCCACCATG ATGTTATATGCTATGTCCCGAT (Spel I) & $200-221(\mathrm{~N})$ & $980 \mathrm{bp}$ \\
\hline & BRSV-NR2 & GTTA CTCGAG CCAATTGGTTCTTGATTGCCTC (Xhol) & $1127-1147(N)$ & \\
\hline \multirow[t]{2}{*}{ BPIV3 } & BPIV3 MF1 & CTAG TCTAGAAACGAACAAAGGAAGGCAAT(Xbal) & 3834-3853 & $881 \mathrm{bp}$ \\
\hline & BPIV3 MR1 & CGC GGATCCATGATGCCCATATAACCAGA (BamHI) & 4676-4695 & \\
\hline \multirow[t]{2}{*}{ IDV } & IDV-F & GATCGACTAGTCGCCACCATG acgtcaatgatatcattgaca(Spel I) & 68-88 & $2135 \mathrm{bp}$ \\
\hline & IDV-R & GTTACTCGAGC ttcaattgcctctcccatcga (Xhol) & $2150-2170$ & \\
\hline
\end{tabular}

\section{Optimization of the Multiplex Reaction System}

To improve the performance of the multiplex reaction system and reduce the interference among the fluorophores, the parameters including primer concentration, probe concentration, annealing temperatures, and cycling conditions were selected for optimization. The optimized multiple real-time PCR reactions were further evaluated by using the nucleic acids isolated from related pathogens including BVDV, BoHV-1, BPIV3, IDV, and BRSV. Amplification was carried out on Applied Biosystems QuantStudio 5 (Thermo Fisher Scientific). We found that a good amplification effect can be achieved when the total reaction system is $10 \mu \mathrm{L}$. Consistently, the optimized multiplex reaction system could efficiently recognize the specific pathogen with the corresponding primer/probe set (Figures 3A-F). By using the 10-fold serial diluted plasmid standards, we further validated the amplification efficiency and detection limits, and found that the sample with the concentrations as low as $1 \times 10^{1}$ copies $/ \mu \mathrm{L}$ are detectable. Unfortunately, this lowest number of nucleic acid copies per unit volume $\left(1 \times 10^{1}\right.$ copies $\left./ \mu \mathrm{L}\right)$ was not able to be detected in $95 \%$ of BVDV and IDV detection. Therefore, the lowest acceptance limit was defined as $1 \times 10^{2}$ copies/ $\mu \mathrm{L}$ for BVDV and IDV. The cutoff $\mathrm{Ct}$ value for BVDV positivity was defined at 36 , which means the sample with a $\mathrm{Ct}$ value less than or equal to $36(\leq 36)$ was considered as positive, but higher than $36(>36)$ are negative. The cutoff Ct value for BoHV-1 and BPIV 3 positivity was defined at 36 , and the cutoff Ct value for IDV positivity was defined at 37 (Figures 4A-E).

\section{Repeatability of the Multiplex Real-Time PCR Assay}

To assess the repeatability of the multiplex real-time PCR assay, four dilutions of the plasmid standards ranging from $10^{3}$ to $10^{6}$ 
A

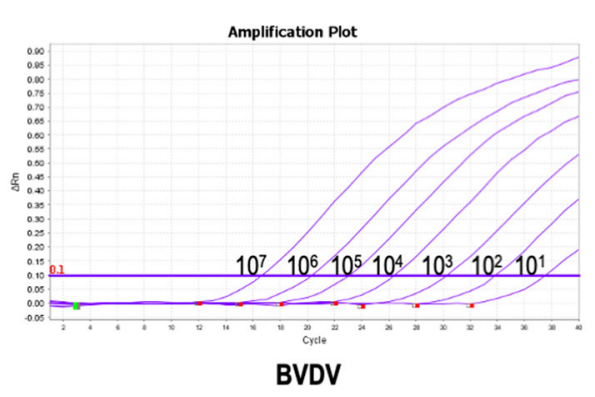

B

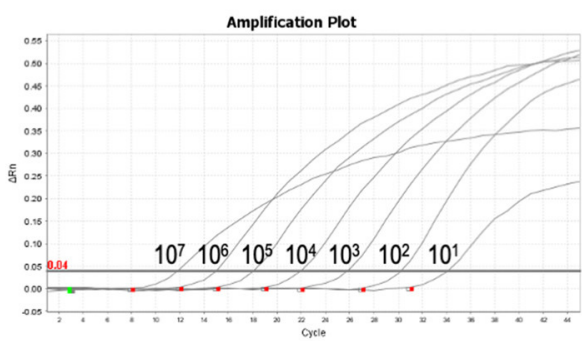

BoHV-1

C

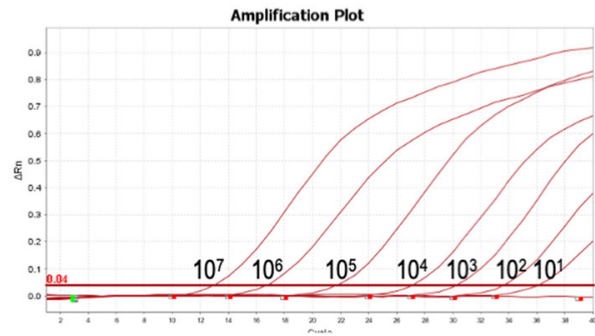

BPIV3

D

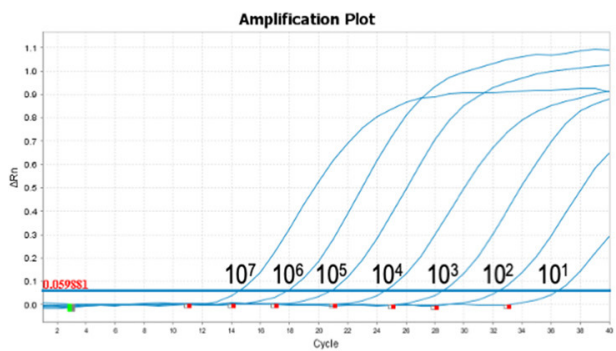

BRSV

E

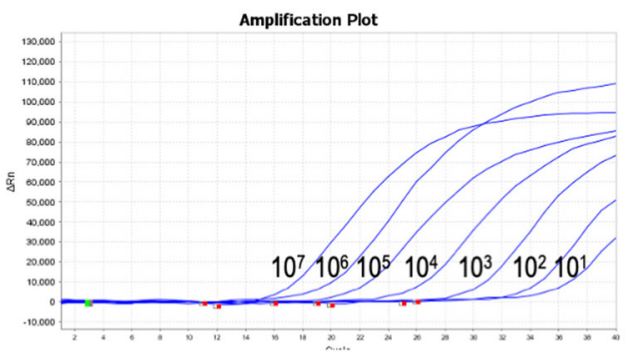

IDV
$\mathbf{F}$

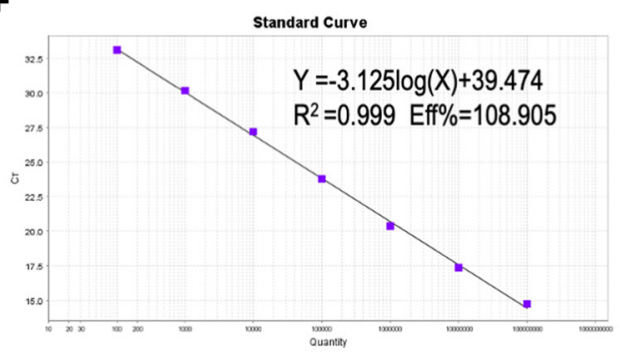

BVDV

G

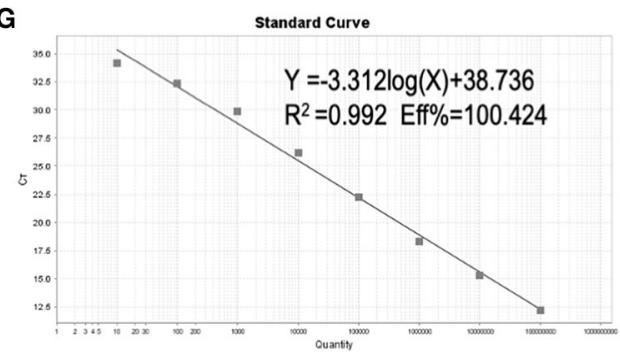

BoHV-1

H

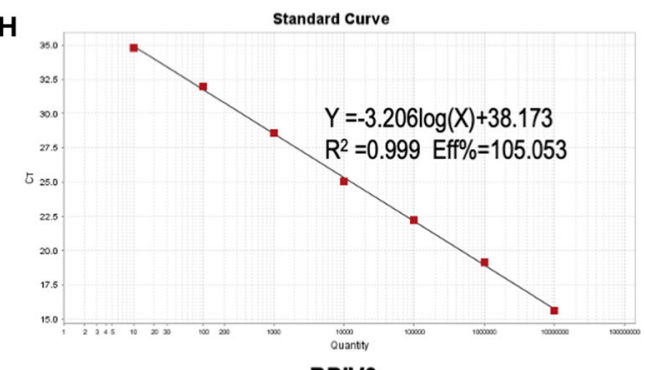

BPIV3

I

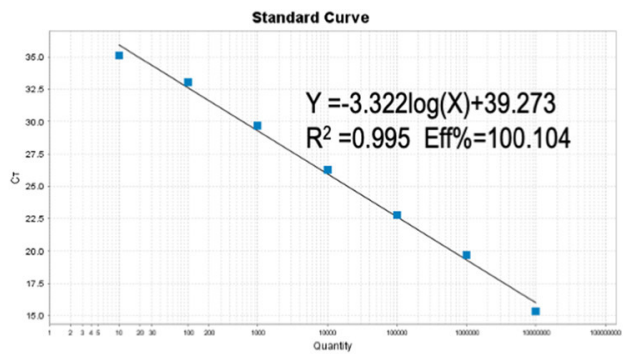

BRSV

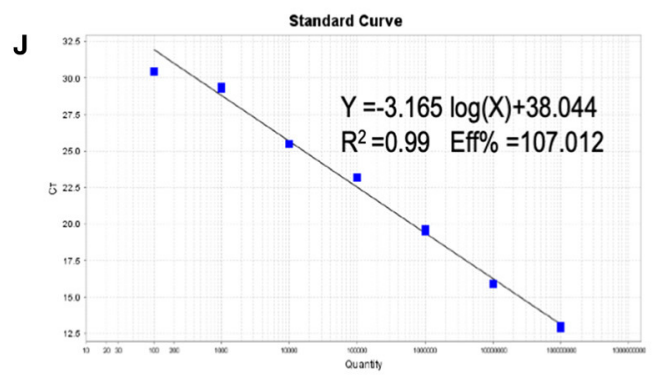

IDV

FIGURE 2 | Preparation of plasmid standards: (A-E): amplification curves (X-axis: Cycle, Y-axis: $\triangle$ Rn) of BVDV, BPIV3, BRSV, BoHV-1 and IDV for each plasmid standard with concentrations ranging from $1 \times 10^{7}$ copies/ $\mu \mathrm{L}$ to $1 \times 10^{1}$ copies $/ \mu \mathrm{L} ;(\mathbf{F}-\mathbf{H})$ : standard curves of plasmid standards of BVDV, BPIV3, BRSV, BoHV-1and IDV. (F): BVDV: $Y=-3.125 \log (X)+39.474 R^{2}=0.999 \mathrm{Eff} \%=108.905 ;(\mathbf{G}): B \circ H V-1: Y=-3.312 \log (X)+38.736 R^{2}=0.992 \mathrm{Eff} \%=100.424 ;(\mathbf{H}): B P I V 3: Y=$ $-3.206 \log (X)+38.173 R^{2}=0.999 \mathrm{Eff} \%=105.053 ;$ I: BRSV: $Y=-3.322 \log (X)+39.273 R^{2}=0.995 E f f \%=100.104 ;(J): I D V: Y=-3.165 \log (X)+38.044 R^{2}=0.99$ $\mathrm{Eff} \%=107.012$. 


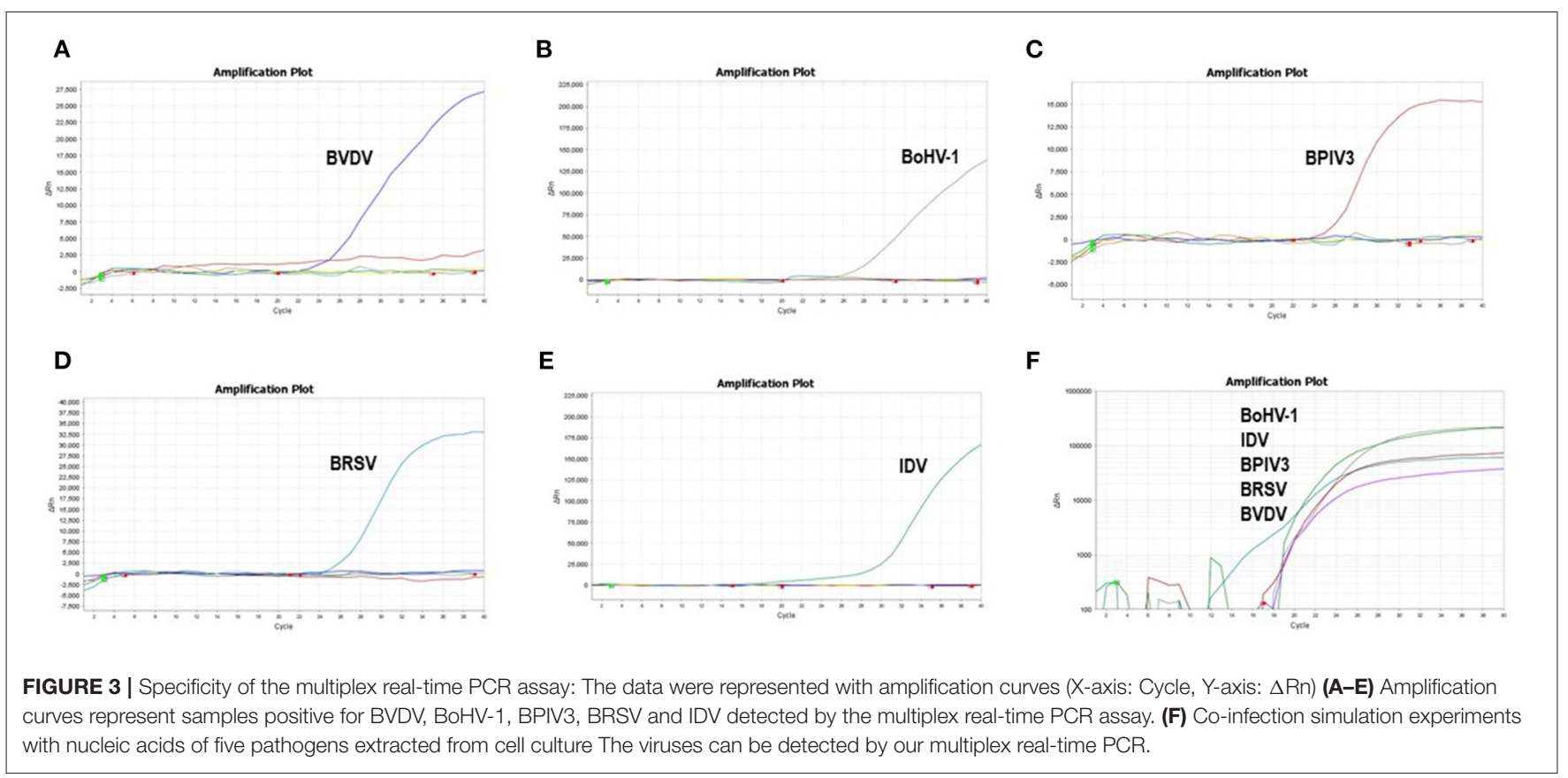

are used for intra-batch and inter-batch repetitions. The standard deviation and coefficient of variation were calculated based on the $\mathrm{Ct}$ values obtained from three replicates. As shown in Table 3, the coefficient of variation is $<3 \%$, indicating the method has good repeatability.

\section{Clinical Sample Detection}

To further verify its clinical applicability for the differential diagnoses of BRDC associated viral pathogens, 213 clinical samples collected from the cattle with clinical signs of BRDC were tested. Among them, 63 (29.577 \%) were detected as positive for BVDV, 55 (25.822 \%) were detected as positive for BoHV-1, 32 (15.023\%) were detected as positive for BPIV3, $6(2.817 \%)$ were detected as positive for BRSV. Interestingly, 15 (7.042 \%) IDV positive sample was also detected (Figure 5). Among all samples, 52 (24.413\%) clinical specimens were co-infected with two or more than two pathogens. Of note, 26(12.207 \%) clinical samples were co-infected with BoHV-1and BPIV3, among which the co-infections of BPIV3 and BoHV1 were the most serious (Table 4), indicating that BVDV and BoHV-1 is widespread in the dairy herds in China and exist serious co-infections.

\section{DISCUSSION}

BRDC is an important disease that plagues the cattle industry and causes significant economic losses (1). Since BRDC is a muti-factorial disease, involving both viral and bacterial pathogens (26). The early diagnosis and detection of BRDC is of great economic and clinical significance (27). At present, the commonly used detection assays are classified into antigen detection and antibody detection (28). Conventional RT-PCR and PCR have been widely applied for pathogen detection.
However, this method is only suitable for infection by a single pathogen, and time-consuming $(29,30)$. As bovine respiratory disease syndrome is mainly caused by co-infection of multiple pathogens, it is urgent to develop a rapid and convenient detection method to simultaneously the pathogens causing BRDC. So far, a variety of detection methods have been developed for the BRDC diagnosis $(3,21)$. For instance, Liu et al. developed a nanoparticle-assisted PCR assay for detection of BRSV, BoHV1, BVDV, and BPIV3 with a detection limit of $1.43 \times 10^{2}$ copies of recombinant plasmids per reaction (31). Leenadevi et al. developed a one-step multiplex real time RT-PCR for the detection of BRSV, BoHV-1 and BPIV3. The assay was rapid, highly repeatable, specific and had a sensitivity of $97 \%$ in detecting $10^{2}$ copies of BRSV, BoHV-1 and BPIV3 (22). Mari et al. developed a multiplex real-time RT-PCR assay for BVDV-1, BVDV-2 and HoBi-like pestivirus. The assay was found to be sensitive, specific and repeatable, ensuring detection of as few as $10^{0}-10^{1}$ viral RNA copies (32). Although these methods have good specificity and sensitivity, the detected pathogens were only limited to BVDV, BoHV-1, or BPIV3. The accumulating studies have found that IDV and BRSV are also highly associated with bovine respiratory disease syndrome $(19,27)$. Therefore, the assays that are capable of detecting all these five pathogens are needed. In this study, primers and probes that could specifically recognize the dedicated pathogens were designed in the highly conserved regions. To improve the amplification efficiency of different primers and probes, the annealing temperature of the primers was set at $57^{\circ} \mathrm{C}$, the annealing temperature of the probe was set at $67^{\circ} \mathrm{C}$. Notably, in this developed assay, the primer/probe set of BVDV showed the lowest amplification. One possible explanation is that the fluorescence of Cy5 was the weakest and very susceptible to interference from other fluorophores due to its own physical 
A

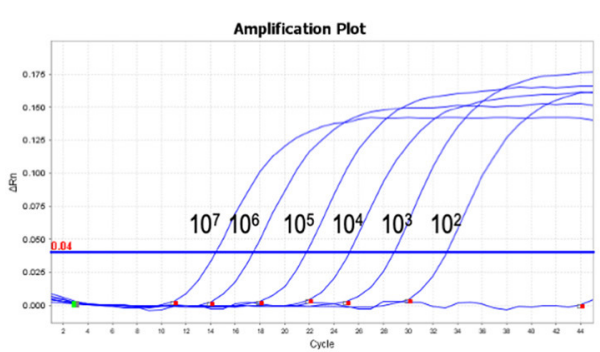

BVDV

B

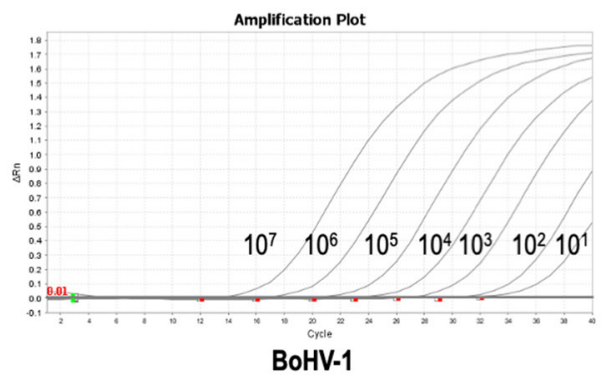

C

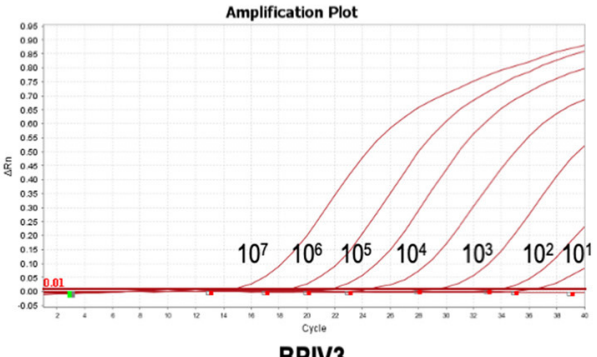

D

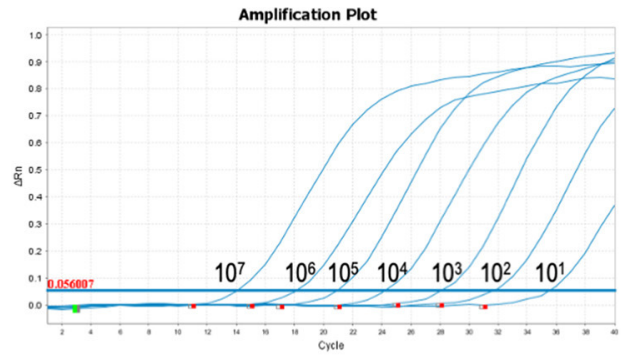

BRSV

E

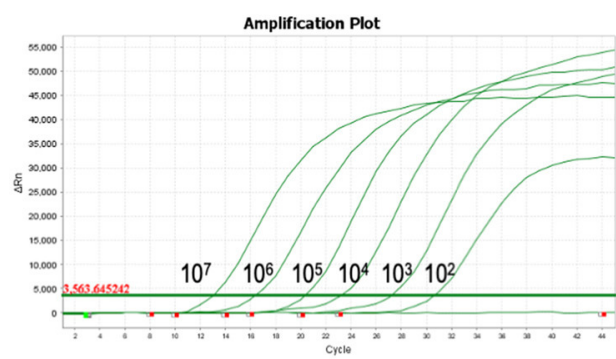

IDV

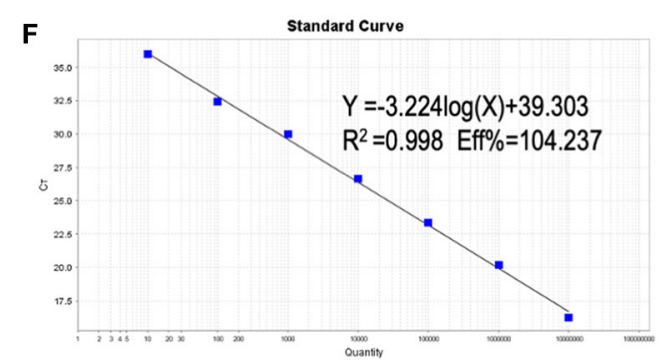

BVDV

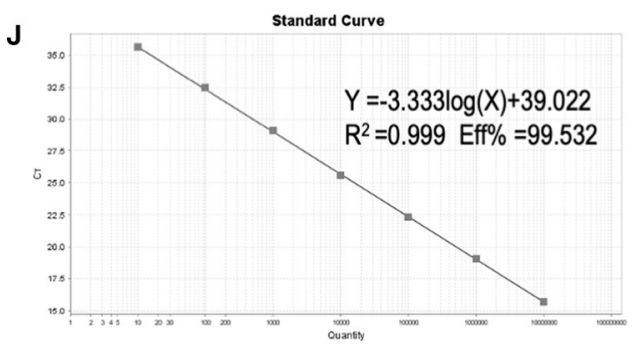

BoHV-1

H

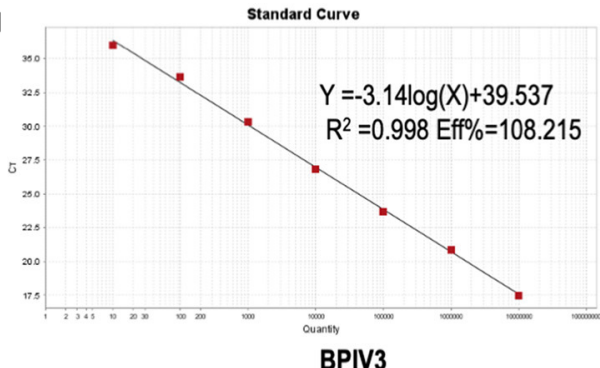

I

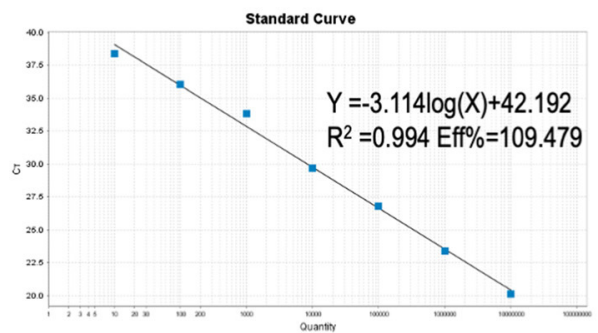

BRSV

J

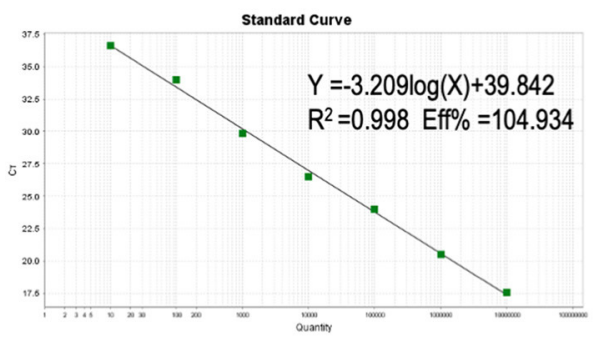

IDV

FIGURE 4 | Sensitivity of the multiplex real-time PCR assay: (A-E) amplification curves (X-axis: Cycle, Y-axis: $\triangle R$ Rn) of plasmid standards of BVDV, BoHV-1,BPIV3,BRSV and IDV detected by multiplex real-time PCR. (F-J) standard curves of plasmid standards of BVDV, BoHV-1, BPIV3, BRSV and IDV. F: BVDV: Y $=-3.224 \log (X)+39.303 R^{2}=0.998 \mathrm{Eff} \%=104.237 ;(\mathbf{G}): B o H V-1: Y=-3.333 \log (X)+39.022 R^{2}=0.999 \mathrm{Eff} \%=99.532 ;(\mathbf{H}): B P I V 3: Y=-3.14 \log (X)+39.537 R^{2}$ $=0.998 \mathrm{Eff} \%=108.215 ;(\mathbf{I}): \mathrm{BRSV}: Y=-3.114 \log (X)+42.192 R^{2}=0.994 \mathrm{Eff} \%=109.479 ;(\mathbf{J}):$ IDV: $Y=-3.209 \log (X)+39.842 R^{2}=0.998 \mathrm{Eff} \%=104.934$. 
properties (30). Despite the optimization such as primer/probe concentration and annealing temperature, the improvement effect was not significant. Among all these viruses, BoHVlexhibited the highest amplification efficiency probably due to its

TABLE 3 | Repeatability of the multiplex real-time PCR assay.

\begin{tabular}{|c|c|c|c|c|c|}
\hline \multirow[t]{2}{*}{ Virus } & \multirow{2}{*}{$\begin{array}{l}\text { Concentration } \\
\text { of template } \\
\text { (copies } / \mu \mathrm{L} \text { ) }\end{array}$} & \multicolumn{2}{|c|}{$\begin{array}{l}\text { Intra-coefficient } \\
\text { of variation }\end{array}$} & \multicolumn{2}{|c|}{$\begin{array}{l}\text { Inter-coefficient } \\
\text { of variation }\end{array}$} \\
\hline & & $X \pm S D$ & Cv(\%) & $\mathrm{X} \pm \mathrm{SD}$ & CV(\%) \\
\hline \multirow[t]{4}{*}{ BVDV } & $10^{6}$ & $19.323 \pm 0.134$ & 0.70 & $19.319 \pm 0.227$ & 1.17 \\
\hline & $10^{5}$ & $23.188 \pm 0.016$ & 0.07 & $23.140 \pm 0.153$ & 0.66 \\
\hline & $10^{4}$ & $26.157 \pm 0.044$ & 0.17 & $26.411 \pm 0.366$ & 1.39 \\
\hline & $10^{3}$ & $29.904 \pm 0.123$ & 0.41 & $29.598 \pm 0.281$ & 0.95 \\
\hline \multirow[t]{4}{*}{$\mathrm{BOHV}-1$} & $10^{6}$ & $18.807 \pm 0.034$ & 0.18 & $18.874 \pm 0.136$ & 0.72 \\
\hline & $10^{5}$ & $22.414 \pm 0.038$ & 0.17 & $22.428 \pm 0.042$ & 0.19 \\
\hline & $10^{4}$ & $26.785 \pm 0.089$ & 0.33 & $26.727 \pm 0.137$ & 0.51 \\
\hline & $10^{3}$ & $29.617 \pm 0.179$ & 0.60 & $29.428 \pm 0.315$ & 1.07 \\
\hline \multirow[t]{4}{*}{ BRSV } & $10^{6}$ & $21.283 \pm 0.038$ & 1.70 & $21.759 \pm 0.465$ & 1.45 \\
\hline & $10^{5}$ & $25.067 \pm 0.032$ & 0.12 & $25.177 \pm 0.084$ & 0.33 \\
\hline & $10^{4}$ & $28.681 \pm 0.023$ & 0.80 & $28.852 \pm 0.45$ & 1.56 \\
\hline & $10^{3}$ & $32.118 \pm 0.125$ & 0.39 & $33.081 \pm 1.14$ & 2.14 \\
\hline \multirow[t]{4}{*}{ BPIV3 } & $10^{6}$ & $20.815 \pm 0.064$ & 0.31 & $20.694 \pm 0.362$ & 1.75 \\
\hline & $10^{5}$ & $24.435 \pm 0.012$ & 0.53 & $24.348 \pm 0.559$ & 2.29 \\
\hline & $10^{4}$ & $27.510 \pm 0.438$ & 0.25 & $27.400 \pm 0.285$ & 1.04 \\
\hline & $10^{3}$ & $30.747 \pm 0.028$ & 0.09 & $30.640 \pm 0.288$ & 0.94 \\
\hline \multirow[t]{4}{*}{ IDV } & $10^{6}$ & $19.278 \pm 0.042$ & 0.21 & $19.425 \pm 0.55$ & 2.80 \\
\hline & $10^{5}$ & $22.185 \pm 0.349$ & 1.57 & $22.650 \pm 0.104$ & 0.45 \\
\hline & $10^{4}$ & $25.070 \pm 0.074$ & 0.30 & $25.608 \pm 0.389$ & 1.50 \\
\hline & $10^{3}$ & $28.230 \pm 0.099$ & 0.35 & $28.664 \pm 0.243$ & 0.85 \\
\hline
\end{tabular}

double-stranded DNA structure which enables the amplification more efficient.

In the clinical samples tested, the highest prevalence was observed for BoHV-1 and BVDV, while the infection rate of BRSV is relatively lower. Our observations were consistent with the previous reports showing the prevalence of BoHV-1 and BVDV in China was $\sim 40$ and $50.10 \%$, respectively $(11,33)$. As reported previously, the infection rate of BPIV3 and BRSV is relatively lower (34). However, a survey in Slovenia showed that the most prevalent virus was BRSV instead, followed by $\mathrm{BCoV}, \mathrm{BPIV} 3$, and BVDV, while BoHV-1 was less frequently detected (35). The observed differences of BRSV and BoHV-1 prevalence indicated that the major causes of BRDC in different country/regions need to be determined by conducting routine surveillance. In addition, we found that the positive rate of IDV is more than $7.042 \%$, suggesting that a certain prevalence of IDV

TABLE 4 | The number of clinical specimens with co-infection.

\begin{tabular}{lc}
\hline Co-infection & Number \\
\hline BoHV-1, BPIV3, IDV & 3 \\
BVDV, BoHV-1, BPIV3 & 5 \\
BVDV, BoHV-1, BPIV3 & 5 \\
BoHV-1, BPIV3 & 15 \\
BPIV3, IDV & 1 \\
BoHV-1, IDV & 1 \\
BVDV, BoHV-1 & 11 \\
BPIV3, BRSV & 1 \\
BVDV, IDV & 4 \\
BPIV3, BRSV, IDV & 1 \\
BoHV-1, BRSV & 1 \\
BVDV, BPIV3 & 1 \\
BoHV-1, BPIV3, BRSV & 1
\end{tabular}
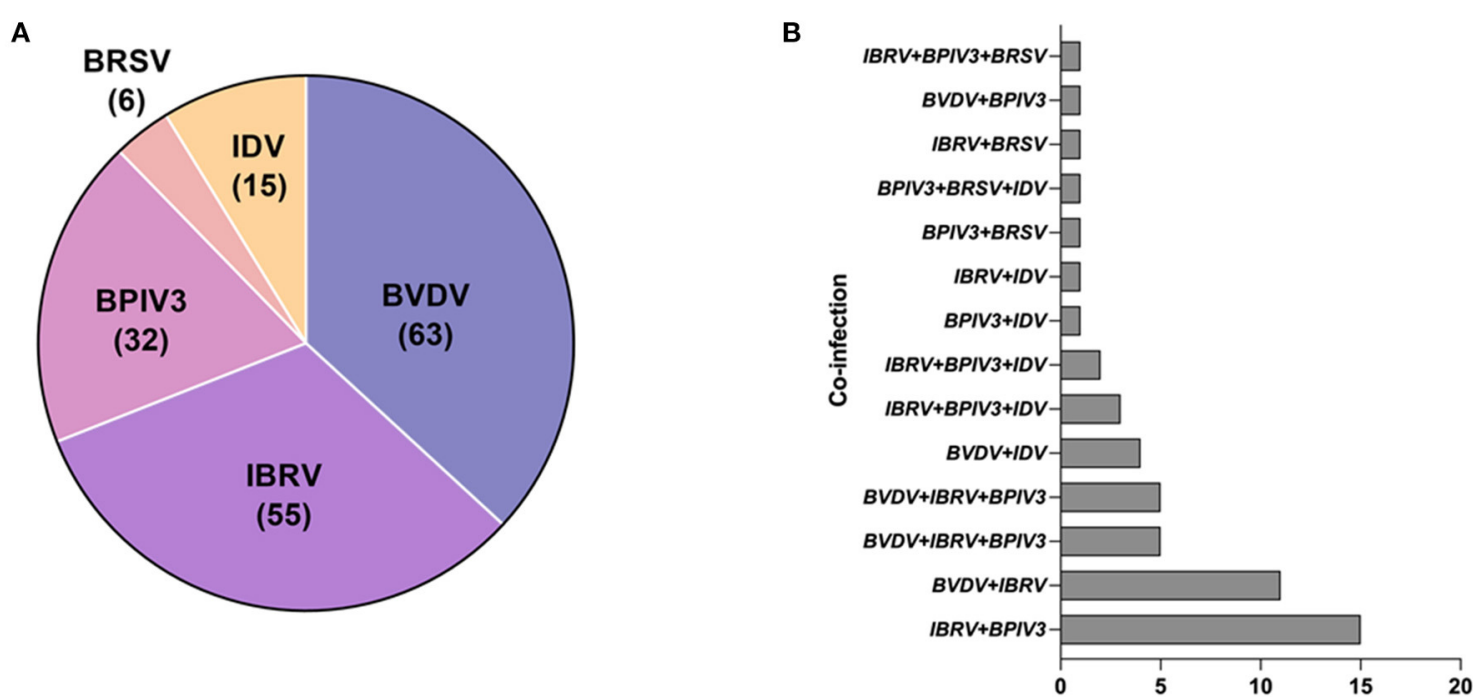

FIGURE 5 | Clinical sample detection: (A) The distribution of clinical samples that are positive for BVDV, BoHV-1, BPIV3, BRSV or IDV. (B) The co-infection incidence among BVDV, IBRV, BPIV3, BRSV and IDV. 
occurs in the northeast part of China. The surveillance of IDV in cattle population in China needs to be performed.

Due to the sampling season and sampling method, the positive rate may be affected. As reported, the high incidence of respiratory diseases mainly occurs in spring (4). while the clinical samples used in this study were collected from the northeast part of China during 2019-2021. Notably, we found that the dual infections (BoHV-1 and BPIV3, BVDV and BoHV-1) were identified most often in the cattle with BRD symptoms. Due to the limited sample size, further investigation is required to verify the observation. In conclusion, this study established efficient multiple real-time PCR detection method which can detect the five major viral pathogens causing BVDV, BoHV-1, BRSV, BPIV3, and IDV, and provided support for the clinical surveillances.

\section{DATA AVAILABILITY STATEMENT}

The original contributions presented in the study are included in the article/supplementary material, further inquiries can be directed to the corresponding authors.

\section{REFERENCES}

1. Bell RL, Turkington HL, Cosby SL, The bacterial and viral agents of BRDC: immune evasion and vaccine developments. Vaccines (Basel). (2021) 9. doi: 10.3390/vaccines9040337

2. Liu Z, Li J, Liu Z, Li J, Li Z, Wang C, et al. Development of a nanoparticleassisted PCR assay for detection of bovine respiratory syncytial virus. BMC Vet Res. (2019) 15:110. doi: 10.1186/s12917-019-1858-0

3. Thanthrige-Don N, Lung O, Furukawa-Stoffer T, Buchanan C, Joseph T, Godson DL, et al. A novel multiplex PCR-electronic microarray assay for rapid and simultaneous detection of bovine respiratory and enteric pathogens. $J$ Virol Methods. (2018) 261:51-62. doi: 10.1016/j.jviromet.2018.08.010

4. Guo $\mathrm{T}$, Zhang J, Chen $\mathrm{X}$, Wei $\mathrm{X}$, Wu C, Cui Q, et al. Investigation of viral pathogens in cattle with bovine respiratory disease complex in Inner Mongolia, China. Microb Pathog. (2021) 153:104594. doi: 10.1016/j.micpath.2020.104594

5. Mehinagic K, Pilo P, Vidondo B, Stokar-Regenscheit N. Coinfection of Swiss cattle with bovine parainfluenza virus 3 and Mycoplasma bovis at acute and chronic stages of bovine respiratory disease complex. J Vet Diagn Invest. (2019) 31:674-80. doi: 10.1177/1040638719861686

6. Gershwin LJ, Van Eenennaam AL, Anderson ML, McEligot HA, Shao MX, Toaff-Rosenstein R, et al. Single Pathogen Challenge with Agents of the Bovine Respiratory Disease Complex. PLoS ONE. (2015) 10:e0142479. doi: 10.1371/journal.pone.0142479

7. Walz PH, Chamorro MF, Falkenberg SM, Passeler T, van der Meer F, Woolums AR. A bovine viral diarrhea virus: An updated American College of Veterinary Internal Medicine consensus statement with focus on virus biology, hosts, immunosuppression, and vaccination. J Vet Intern Med. (2020) 34:1690-706. doi: 10.1111 /jvim.15816

8. Wenzhi Xue HCM. Identification of bovine viral diarrhea virus receptor in different cell types. Vet Microbiol. (1996) 49:67-79. doi: 10.1016/0378-1135(95)00167-0

9. Peddireddi L, Foster KA, Poulsen EG, An B, Hoang QH, O'Connell $\mathrm{C}$, et al. Molecular detection and characterization of transient bovine viral diarrhea virus (BVDV) infections in cattle commingled with ten BVDV persistently infected cattle. J Vet Diagn Invest. (2018) 30:413-22. doi: $10.1177 / 1040638717753962$

10. Baxi M, McRae D, Baxi S, Greiser-Wilke I, Vilcek S, Amoako K, et al. A one-step multiplex real-time RT-PCR for detection and typing of bovine viral diarrhea viruses. Vet Microbiol. (2006) 116:37-44. doi: 10.1016/j.vetmic.2006.03.026

\section{AUTHOR CONTRIBUTIONS}

XY, YMZ, FX, and JZ designed the study, reviewed, and edited the manuscript. ZJ, WW, MJY, and JL collected the samples. ZJ performed the experiments. ZJ and XY wrote and edited the manuscript. All the authors read and approved the final manuscript.

\section{FUNDING}

This work was supported by the Natural Science Foundation of Heilongjiang Province JQ2021C005 (XY). The funders had no role in study design, data collection and analysis, decision to publish, or preparation of the manuscript.

\section{ACKNOWLEDGMENTS}

The authors would like to thank the members from Yin Laboratory for their critical suggestions.

11. Chen X, Wang X, Qi Y, Wen X, Li C, Liu X, et al. Meta-analysis of prevalence of bovine herpes virus 1 in cattle in Mainland China. Acta Trop. (2018) 187:37-43. doi: 10.1016/j.actatropica.2018.07.024

12. Xu J, Zhang X, Zhou S, Shen J, Yang D, Wu J, et al. A DNA aptamer efficiently inhibits the infectivity of Bovine herpesvirus 1 by blocking viral entry. Sci Rep. (2017) 7:11796. doi: 10.1038/s41598-017-10070-1

13. Hou P, Wang $\mathrm{H}$, Zhao G, He C, He H. Rapid detection of infectious bovine Rhinotracheitis virus using recombinase polymerase amplification assays. BMC Vet Res. (2017) 13:386. doi: 10.1186/s12917-017-1284-0

14. Muylkens B, Thiry J, Kirten P, Schynts F, Thiry E. Bovine herpesvirus 1 infection and infectious bovine rhinotracheitis. Vet Res. (2007) 38:181-209. doi: 10.1051/vetres:2006059

15. Ellis JA. Bovine Parainfluenza-3 Virus. Vet Clin North Am Food Anim Pract. (2010) 26:575-93. doi: 10.1016/j.cvfa.2010.08.002

16. Sarmiento-Silva RE, Nakamura-Lopez Y, Vaughan G. Epidemiology, molecular epidemiology and evolution of bovine respiratory syncytial virus. Viruses. (2012) 4:3452-67. doi: 10.3390/v4123452

17. Valarcher JF, Taylor G. Bovine respiratory syncytial virus infection. Vet Res (2007) 38:153-80. doi: 10.1051/vetres:2006053

18. Su S, Fu X, Li G, Kerlin F, Veit M. Novel Influenza D virus: Epidemiology, pathology, evolution and biological characteristics. Virulence. (2017) 8:158091. doi: 10.1080/21505594.2017.1365216

19. Zhang X, Outlaw C, Olivier AK, Woolums A, Epperson W, Wan XF. Pathogenesis of co-infections of influenza D virus and Mannheimia haemolytica in cattle. Vet Microbiol. (2019) 231:246-53. doi: 10.1016/j.vetmic.2019.03.027

20. Zoccola R, Mazzei M, Carrozza ML, Ricci E, Forzan M, Pizzurro F, et al. A newly developed BVDV-1 RT-qPCR Taqman assay based on Italian isolates: evaluation as a diagnostic tool. Folia Microbiol (Praha). (2017) 62:279-86. doi: 10.1007/s12223-017-0497-8

21. Kishimoto M, Tsuchiaka S, Rahpaya SS, Hasebe A, Otsu K, Sugimura S. et al. Development of a one-run real-time PCR detection system for pathogens associated with bovine respiratory disease complex. J Vet Med Sci. (2017) 79:517-23. doi: 10.1292/jvms.16-0489

22. L. Thonur. One-step multiplex real time RT-PCR for the detection of bovine respiratory syncytial virus, bovine herpesvirus 1 and bovine parainfluenza virus 3. BMC Vet Res. (2012) 8:1746-6148. doi: 10.1186/17466148-8-37

23. Zhu YM, Shi HF, Gao YR, Xin JQ, Liu NH, Xiang WH, et al. Isolation and genetic characterization of bovine parainfluenza virus type 3 from cattle in China. Vet Microbiol. (2011) 149:446-51. doi: 10.1016/j.vetmic.2010.11.011 
24. Liu H, Li Y, Gao M, Wen K, Jia Y, Liu X, et al. Complete genome sequence of a bovine viral diarrhea virus 2 from commercial fetal bovine serum. $J$ Virol. (2012) 86:10233. doi: 10.1128/JVI.01581-12

25. Wang C, Li S, Jia H, Chen G, Fang Y, Zeng S, et al. Monoclonal and oligoclonal TCR AV and BV gene usage in CD4(+) T cells from pigs immunised with Cstrain CSFV vaccine. Sci Rep. (2018) 8:1655. doi: 10.1038/s41598-018-19974-y

26. Oguejiofor CF, Thomas C, Cheng Z, Wathes DC. Mechanisms linking bovine viral diarrhea virus (BVDV) infection with infertility in cattle. Animal Health Research Reviews. (2019) 20:72-85. doi: 10.1017/S1466252319000057

27. Sheridan MP, Regev-Shoshani G, Martins J, Vimalanathan S, Miller C. Nitric oxide modulates the immunological response of bovine PBMCs in an in vitro BRDc infection model. Res Vet Sci. (2016) 109:21-8. doi: 10.1016/j.rvsc.2016.09.004

28. Parreno V, Romera SA, Makek L, Rodriguez D, Malacari D, Maidana S, et al. Validation of an indirect ELISA to detect antibodies against BoHV-1 in bovine and guinea-pig serum samples using ISO/IEC 17025 standards. J Virol Methods. (2010) 169:143-53. doi: 10.1016/j.jviromet.2010.07.014

29. I.M. Mackay. Real-time PCR in the microbiology laboratory. Clin Microbiol Infect. (2004) 10:190-212. doi: 10.1111/j.1198-743X.2004. 00722.x

30. Pan Z, Lu J, Wang N, He WT, Zhang L, Zhao W, et al. Development of a TaqMan-probe-based multiplex real-time PCR for the simultaneous detection of emerging and reemerging swine coronaviruses. Virulence. (2020) 11:70718. doi: 10.1080/21505594.2020.1771980

31. Liu C, Liu Y, Liang L, Cui S, Zhang Y. RNA-Seq based transcriptome analysis during bovine viral diarrhoea virus (BVDV) infection. BMC Genomics. (2019) 20:774. doi: 10.1186/s12864-019-6120-4

32. Tsuchiaka S, Masuda T, Sugimura S, Kobayashi S, Komatsu N, Nagai M. et al. Development of a novel detection system for microbes from bovine diarrhea by real-time PCR. J Vet Med Sci. (2016) 78:383-9. doi: 10.1292/jvms.15-0552
33. Sun WW, Meng QF, Cong W, Shan XF, Wang CF, Qian AD. Herd-level prevalence and associated risk factors for Toxoplasma gondii, Neospora caninum, Chlamydia abortus and bovine viral diarrhoea virus in commercial dairy and beef cattle in eastern, northern and northeastern China. Parasitol Res. (2015) 114:4211-8. doi: 10.1007/s00436-015-4655-0

34. Shen Y, Liu J, Zhang Y, Ma X, Yue H, Tang C. Prevalence and characteristics of a novel bovine adenovirus type 3 with a natural deletion fiber gene. Infect Genet Evol. (2020) 83:104348. doi: 10.1016/j.meegid.2020.104348

35. Tomislav Paller PH, Pogačnik M, Toplak I. The prevalence of ten pathogens detected by real-time PCR methods in nasal swabs samples collected from live cattle with respiratory disease. Slov Vet Res. (2017) 54.

Conflict of Interest: The authors declare that the research was conducted in the absence of any commercial or financial relationships that could be construed as a potential conflict of interest.

Publisher's Note: All claims expressed in this article are solely those of the authors and do not necessarily represent those of their affiliated organizations, or those of the publisher, the editors and the reviewers. Any product that may be evaluated in this article, or claim that may be made by its manufacturer, is not guaranteed or endorsed by the publisher.

Copyright (c) 2022 Zhang, Wang, Yang, Lin, Xue, Zhu and Yin. This is an open-access article distributed under the terms of the Creative Commons Attribution License (CC $B Y)$. The use, distribution or reproduction in other forums is permitted, provided the original author(s) and the copyright owner(s) are credited and that the original publication in this journal is cited, in accordance with accepted academic practice. No use, distribution or reproduction is permitted which does not comply with these terms. 